\title{
Analysis of quantitative traits in barley by the use of Amplified Fragment Length Polymorphisms
}

\author{
W. POWELL*, W. T. B. THOMAS, E. BAIRD, P. LAWRENCE, A. BOOTH, B. \\ HARROWER, J. W. MCNICOL \& R. WAUGH \\ Department of Cell \& Molecular Genetics, Scottish Crop Research Institute, Invergowrie, Dundee DD2 5DA, \\ Scotland, UK
}

\begin{abstract}
Amplified fragment length polymorphisms (AFLPs) produced with EcoRI and PstI both in combination with MseI restriction enzymes have been studied in the parents of four barley mapping populations. Averages of 15.9 and 18.7 polymorphic products per assay were produced for the EcoRI/MseI and PstI/MseI combinations, respectively. There was some evidence of interaction between cross combinations and restriction enzyme combinations, with Pst $/$ MseI generating relatively more polymorphic products than EcoRI/MseI in the Blenheim $\times$ E224/3 cross combination, the least polymorphic of the four. Three hundred and ninety-eight AFLP products, using both restriction enzyme combinations, were generated in a doubled haploid population of 68 lines produced from the Blenheim $\times$ E224/3 cross. These were added to existing marker data for the cross to study the effects of incorporation of AFLPs produced by different restriction enzyme combinations upon genetic maps. Addition of the AFLP data resulted in greater genome coverage, both through linking previously separate groups and extensions to other groups. This increase in coverage appeared to result from AFLPs sampling some different regions of the genome compared to RAPDs and RFLPs, as the map distances spanned by the RAPD and RFLP linkage groups were similar with and without incorporation of AFLPs. There was also evidence that the EcoRI and PstI restriction enzymes sampled different regions of the genome. The revised maps were used in scanning for QTLs controlling a subset of 12 economically important traits measured in the cross. Overall, the QTLs accounted for an average of 53 per cent of the phenotypic variation for the characters. Positive and negative alleles were present in each parent for each character, apart from hot water extract corrected to 1.5 per cent nitrogen (HWEc). Several regions of the genome appeared to be involved in the control of several characters, notably chromosome 2 , the denso locus on chromosome 3, the short arm of chromosome 5 and chromosome 7. Although there was considerable similarity to previous results of QTL mapping for the subset of characters, the greater genome coverage afforded by the inclusion of the AFLPs revealed some new QTL locations.
\end{abstract}

Keywords: AFLPs, barley, genes, mapping, markers, QTL.

\section{Introduction}

The repertoire of genetic marker systems available for genome analysis has increased considerably and falls into two main technological categories: assays based on hybridization and on amplification (Rafalski et al., 1996). Hybridization-based methods have been dominated by Restriction Fragment Length Polymorphism (RFLPs; Botstein et al., 1980) and

*Correspondence. E-mail: wpowel@scri.sari.ac.uk this technology has been widely deployed in plants (Helentjaris \& Burr, 1989). However, the RFLP assay is time consuming and labour intensive. The development of PCR (Mullis et al., 1986) has expanded the range and efficiency of amplification marker systems available. These include: Randomly Amplified Polymorphic DNA (RAPDs; Williams et al., 1990; Welsh \& McClelland, 1990), Simple Sequence Repeat Polymorphisms or microsatellites (SSRPs; Tautz, 1989; Weber \& May, 1989) and Amplified Fragment Length Polymorphisms (AFLPs; Zabeau 
\& Vos, 1993). Two important aspects of a marker system's utility are: information content and multiplex ratio (Powell et al., 1996). Standard measures of diversity may be used to evaluate information content and the multiplex ratio is the number of loci simultaneously analysed per experiment. These two metrics have been used to compare RFLPs, AFLPs, SSRPs and RAPDs in common soybean and barley genotypes (Powell et al., 1994, 1995, 1996). Multiplex ratio and the diversity index were combined to provide an overall measure of marker utility defined as the Marker Index. To date, all comparative studies concur in identifying AFLP as an unique technology with high marker utility arising mainly from its high multiplex ratio.

The AFLP approach has recently been used to identify markers tightly linked to disease resistance loci (Meksem et al., 1995; Thomas et al., 1995a), to fingerprint plant and bacterial genomes (Lin \& Kuo, 1995) and to examine genepool variation in potato cyst nematode populations (Folkertsma et al., 1996). The power of AFLP technology to create rapidly linkage maps in a doubled haploid population of barley has also been recently demonstrated (Becker et al., 1995).

The AFLP approach relies on the selective amplification of small genomic restriction fragments, produced by double digestion with a rare and a frequent cutting restriction enzyme, into which known sequence adaptors have been ligated. As with RFLP, it is reasonable to assume that different restriction enzymes may show different abilities to detect/reveal polymorphism and/or that the polymorphism detected may show a biased distribution throughout the genome. Despite this, the majority of studies published to date have used a combination of EcoRI and MseI restriction enzymes and a relatively small number of primers. The objectives of the present study were therefore to: (i) identify informative protocols (enzymes/primers) for identifying polymorphic AFLP products for barley; (ii) compare the genome distribution of EcoRI/MseI and PstI/ MseI generated AFLP products in comparison with RFLP and RAPD loci; and (iii) examine the utility of AFLP mapping procedures to characterize polygenic, quantitative traits in barley.

\section{Materials and methods}

\section{DNA isolation}

Genomic DNA was isolated from fresh leaf material of Blenheim, E224/3 and $68 \mathrm{DH}$ produced from the $F_{1}$ of the cross between them by a modification of the CTAB method of Saghai-Maroof et al. (1984). The DNA was assessed, quantified and used for AFLP analysis without further purification. DNA from Igri and Franka was supplied by Andreas Graner, Grünbach, Germany. Dicktoo and Morex DNA was supplied by Pat Hayes, Oregon State University, USA.

\section{AFLP analysis}

AFLP methodology was essentially as described by Zabeau \& Vos (1993) with minor modifications. Template DNA was prepared using two combinations of restriction enzymes. Each combination consisted of a pair of enzymes, one of which cut DNA rarely (PstI or EcoRI) and the other cutting frequently (MseI). Genomic DNA $(1.25 \mu \mathrm{g})$ was digested as outlined by Vos et al. (1995) and specific double-stranded adaptors were ligated to the fragment ends. The digested and ligated DNA was then preamplified using either an EcoRI or PstI directed primer and an $M s e I$ directed primer. The primers did not have additional selective nucleotides at the $3^{\prime}$ end (Vos et al., 1995). Adaptor and preamplification primer sequences are given in Table 1. All adaptors and primers used were synthesized by Genset, France.

Preamplification was performed in a total volume of $25 \mu \mathrm{L}$ containing $75 \mathrm{ng}$ each of primers M00 and either E00 or P00, $0.2 \mathrm{~mm}$ of all four dNTPs (Pharmacia), $1 \times$ PCR buffer (Perkin Elmer Cetus), $1 \mathrm{U}$ Amplitaq DNA polymerase LD (Perkin Elmer Cetus) and 30 ng of the digested and ligated DNA.

The cycle profile used for preamplification was as follows; denaturation for $30 \mathrm{~s}$ at $94^{\circ} \mathrm{C}$, annealing for $30 \mathrm{~s}$ at $60^{\circ} \mathrm{C}$, extension for $60 \mathrm{~s}$ at $72^{\circ} \mathrm{C}$, for 30 cycles. After preamplification the product was diluted by the addition of $55 \mu \mathrm{L}$ of buffer $(10 \mathrm{~mm}$ Tris- $\mathrm{HCl}, \mathrm{pH}$ $8,0.1 \mathrm{~mm}$ EDTA). Once diluted the preamplification product was used as a template for selective amplification. Selective amplification was carried out using adaptor directed primers with additional selective nucleotides. The primer combinations and their sequences are listed in Appendix I. In each case the EcoRI or MseI primer was end labelled using $\left[\gamma^{33} \mathrm{P}\right]$ ATP and T4 polynucleotide kinase (Gibco) as described by Vos et al. (1995). The selective amplification reactions were carried out in a total volume of $20 \mu \mathrm{L}$, comprising $6.7 \mathrm{ng}$ labelled EcoRI or Pst I primer, $25 \mathrm{ng}$ unlabelled EcoRI or PstI primer, $30 \mathrm{ng}$ MseI primer, $0.2 \mathrm{~mm}$ of all four dNTPs, $1 \times$ PCR buffer (Perkin Elmer Cetus), $0.5 \mathrm{U}$ Amplitaq DNA Polymerase (Perkin Elmer Cetus) and $2 \mu \mathrm{L}$ of template DNA. Reactions were carried 
Table 1 Adaptor and preamplification primer sequences

\begin{tabular}{lll}
\hline Primer & & Sequence \\
\hline EcoRI & Forward adaptor & 5'-CTCGTAGACTGCGTACC \\
EcoRI & Reverse adaptor & 5'-AATTGGTACGCAGTC \\
Pst I & Forward adaptor & 5'-CTCGTAGACTGCGTACATGCA \\
Pst I & Reverse adaptor & 5'-TGTACGCAGTCTAC \\
MseI & Forward adaptor & 5'-GACGATGAGTCCTGAG \\
MseI & Reverse adaptor & 5'-TACTCAGGACTCAT \\
E00 & Preamplification & 5'-GACTGCGTACCAATTC \\
M00 & Preamplification & 5'-CATGAGTCCTGAGTAA \\
P00 & Preamplification & 5'-GACTGCGTACATGCAG \\
\hline
\end{tabular}

out using the cycle profile described by Vos et al. (1995), i.e. one cycle of $94^{\circ} \mathrm{C}$ for $30 \mathrm{~s}, 65^{\circ} \mathrm{C}$ for $30 \mathrm{~s}$, $72^{\circ} \mathrm{C}$ for $60 \mathrm{~s}$, followed by 11 cycles over which the annealing temperature is decreased by $0.7^{\circ} \mathrm{C}$ per cycle, followed by 23 cycles of $94^{\circ} \mathrm{C}$ for $30 \mathrm{~s}, 56^{\circ} \mathrm{C}$ for $30 \mathrm{~s}$ and $72^{\circ} \mathrm{C}$ for $60 \mathrm{~s}$.

All PCR reactions were performed using a Perkin Elmer 9600 thermocycler. Reactions were stopped by the addition of an equal volume of formamide loading buffer (98 per cent formamide, $10 \mathrm{~mm}$ EDTA pH $8,0.5 \mathrm{mg} / \mathrm{mL}$ Bromophenol Blue, $0.5 \mathrm{mg} / \mathrm{mL}$ Xylene Cyanol FF). The samples were denatured at $90^{\circ} \mathrm{C}$ for $5 \mathrm{~min}, 3.5 \mu \mathrm{L}$ of each sample was loaded on to a $40 \mathrm{~cm}, 6$ per cent denaturing polyacrylamide gel (Easigel, Scotlab) which had been preheated by running at $80 \mathrm{~W}$ for $30 \mathrm{~min}$. The samples were then electrophoresed at a constant power of $80 \mathrm{~W}$ for $1 \mathrm{~h} 45 \mathrm{~min}$. Gels were transferred to Whatman $3 \mathrm{MM}$ paper and dried for $2 \mathrm{~h}$ at $80^{\circ} \mathrm{C}$ on a gel drier (Biorad). They were then exposed to autoradiographic film (X-OMAT S, Kodak) to visualize the results.

Results were scored twice, independently, as presence/absence of a given band.

\section{Linkage map construction}

Linkage groups for the Blenheim $\times$ E224/3 DH population were formed using JOINMAP 2.0 (Stam \& Van Ooijen, 1995) with a LOD of 6.0 to form groups and ignoring previous information about linkage groups and orders (Thomas et al., 1995b). Groups were merged where they were known to be separate segments of a chromosome and mapping was carried out with a LOD of 0.05 and a JUMP (Stam \& Van Ooijen, 1995) which varied between 2.8 and 5.0 according to the group. A ripple was performed after the addition of every three markers and the robustness of the ordering was tested by raising the mapping LOD to 0.5. Map distances were calculated using the Kosambi function. JOINMAP 2.0 constructs maps in three cycles (Stam \& Van Ooijen, 1995). In the first cycle, markers which cause the JUMP threshold to be exceeded are excluded until the program has attempted to include all the markers in the group. In the second cycle the program attempts to insert these markers but with the same restriction that if the JUMP threshold is exceeded, they are excluded. In the third cycle markers excluded after the second cycle are inserted in the map but with no restrictions on the JUMP threshold. As the positioning of markers inserted in the third cycle generally gave large rises in the JUMP value, the ordering produced by the second cycle was taken.

\section{Plant material}

Fifty-nine of the Blenheim $\times \mathrm{E} 224 / 3 \mathrm{DH}$ lines were grown in replicated trials at the Scottish Crop Research Institute (SCRI) in the years 1989-92. In addition, replicated trials were grown at Plant Breeding International, Cambridge (PBIC) in 1992 and 1993. A number of characters were measured either on the plots or on samples of seeds harvested from the plots (Thomas et al., 1995b, 1996). In this paper, we will consider a subset of those characters (Table 2).

\section{Data analysis}

QTL analysis was carried out using MQTL 0.95 with significance thresholds being established for an experimental error rate of 0.05 by 1000 random permutations of the data for each character (Tinker \& Mather, 1995). MQTL searches for QTLs using both simple interval mapping (SIM) and simplified compound interval mapping (sCIM). In the latter, 
Table 2 Quantitative traits studied

\begin{tabular}{llll}
\hline Symbol & Character & Units & Description \\
\hline HD & Heading date & Days & From 31 May \\
$\mathrm{Ht}$ & Height & $\mathrm{cm}$ & Ground to collar \\
PY & Plot yield & $\mathrm{t} / \mathrm{ha}$ & Weight of harvested plot @ 13 per cent moisture \\
TGW & 1000 grain weight & $\mathrm{g}$ & (Weight of 100 seed) $\times 10$ \\
$\mathrm{SPW}$ & Specific weight & $\mathrm{kg} / \mathrm{hL}$ & (Weight $(\mathrm{g})$ of $1 \mathrm{~L}$ seed) $/ 10$ \\
$>25$ & Sievings $>2.5 \mathrm{~mm}$ & per cent & (Sample weight $(\mathrm{g})$ passing over sieve $\times 100) /$ total sample weight $(\mathrm{g})$ \\
$\mathrm{GE} 4$ & Germinative energy & per cent & Numbers of seeds from a sample of 100 germinating in $4 \mathrm{~mL}$ after $72 \mathrm{~h}$ \\
$1 \mathrm{GE} 8$ & Water sensitivity & per cent & Numbers of seeds from a sample of 100 germinating in $8 \mathrm{~mL}$ after $72 \mathrm{~h}$ \\
ME & Milling energy & $\mathrm{J}$ & Energy required to mill $5 \mathrm{~g}$ grain sample \\
$\mathrm{GN}$ & Grain nitrogen & per cent & Near-infrared reflectance or combustion analysis of nitrogen in the grain \\
DP & Diastatic power & per cent & Percentage $\beta$-amylase activity in milled sample \\
HWEc & Hot water extract & $\mathrm{L} / \mathrm{kg}$ & Hot water extract of malted grain corrected to 1.5 per cent GN \\
\hline
\end{tabular}

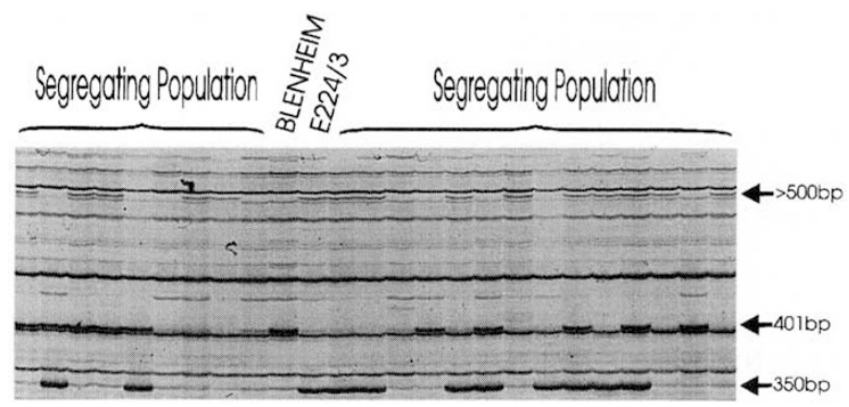

Fig. 1 Segregation of AFLP loci in a doubled haploid population of barley. Template DNA was prepared from EcoRI/MseI digests.

background markers are used to account for possible variation in regions of the genome other than that under test which can refine the location of QTLs revealed by SIM or reveal additional QTLs (Tinker \& Mather, 1995). Some of the mapped markers from Fig. 1 were dropped from the analysis if they were within $1 \mathrm{cM}$ of each other. A total of 222 markers was included in the analysis, 25 of which were background markers. All the background markers were located on the larger chromosome segments and at an approximate spacing of $35 \mathrm{cM}$. The denso locus was deliberately chosen as one of the background markers as previous studies had highlighted its importance in the control of many quantitative traits (Thomas et al., 1991, 1995b, 1996). 'Primary' QTL locations were established where peaks for SIM and sCIM coincided (Tinker \& Mather, 1995). In addition, 'secondary' QTL locations (Tinker et al., 1996) were also established by including effects where the SIM or the sCIM peak was at least equivalent to an increase of LOD 1.0 in the Test Statistic and, in analyses of single environ- ments, the peak exceeded the sCIM threshold at least once.

\section{Results \\ Comparison of restriction enzymes and primer combinations}

Data for the total number of amplification products, number of polymorphic products and the proportion of polymorphic products are given for each primer combination in Appendix I. A total of 39 EcoRI/ MseI and 18 Pst I/MseI combinations were evaluated. Within each restriction enzyme category there are significant differences $(P<0.001)$ between primer pairs for the total number of amplification products generated. The number of polymorphic products differs significantly $(P<0.05)$ for the EcoRI/MseI primer pairs. For each of the three parameters measured there are differences between crosses (Tables 3a,b). There are significant differences between restriction enzymes (EcoR $/$ Mse I vs. Pst $\mathrm{I} /$ $M s e \mathrm{I})$ for the number and proportion of polymorphic products. Furthermore there is a statistically significant interaction $(P<0.05$; Table $3 b)$ between restriction enzyme and crosses for the proportion of polymorphic products detected. This is manifested in the different response of Blenheim $\times$ E224/3 and Igri $\times$ Franka template DNA compared to that of the other crosses to PstI/MseI primers (Table 3a).

\section{Map construction}

An example of segregating AFLP products in the Blenheim $\times$ E224/3 DH population obtained from $E c o \mathrm{RI} / M s e$ I template DNA is given in Fig. 1. A total of 398 polymorphic AFLP markers were obtained, 
Table 3a A comparison of different restriction enzyme combinations in the parents of four barley mapping populations

\begin{tabular}{|c|c|c|c|c|c|c|}
\hline & \multicolumn{2}{|c|}{$\begin{array}{c}\text { Total number of amplified } \\
\text { products }\end{array}$} & \multicolumn{2}{|c|}{$\begin{array}{l}\text { Number of polymorphic } \\
\text { products }\end{array}$} & \multicolumn{2}{|c|}{$\begin{array}{l}\text { Proportion of polymorphic } \\
\text { products }\end{array}$} \\
\hline & EcoRI/MseI & Pst $\mathrm{I} / M s e \mathrm{I}$ & EcoRI/MseI & Pst $\mathrm{I} / M s e \mathrm{I}$ & EcoRI/MseI & Pst $\mathrm{I} / M s e \mathrm{I}$ \\
\hline Blenheim $\times E 224 / 3$ & $92.3 \pm 3.90$ & $88.8 \pm 6.01$ & $8.5 \pm 1.03$ & $13.7 \pm 1.59$ & $0.092 \pm 0.0049$ & $0.154 \pm 0.0096$ \\
\hline Dicktoo $\times$ Morex & $102.4 \pm 3.95$ & $104.4 \pm 6.42$ & $21.9 \pm 1.05$ & $23.6 \pm 1.70$ & $0.213 \pm 0.0067$ & $0.226 \pm 0.0109$ \\
\hline Igri $\times$ Franka & $90.8 \pm 3.90$ & $82.3 \pm 6.42$ & $10.8 \pm 1.03$ & $11.5 \pm 1.70$ & $0.119 \pm 0.0055$ & $0.138 \pm 0.0102$ \\
\hline Lina $\times H$. spontaneum & $90.0 \pm 4.00$ & $91.0 \pm 6.66$ & $22.4 \pm 1.06$ & $25.8 \pm 1.76$ & $0.248 \pm 0.0076$ & $0.283 \pm 0.0131$ \\
\hline
\end{tabular}

Table 3b Analysis of variance for various parameters influencing the efficiency of AFLP assays in barley

\begin{tabular}{lrccc}
\hline & d.f. & $\begin{array}{c}\text { Total number of } \\
\text { amplified products } \\
\text { MS }\end{array}$ & $\begin{array}{c}\text { Number of } \\
\text { polymorphic products } \\
\text { MS }\end{array}$ & $\begin{array}{c}\text { Proportion of } \\
\text { polymorphic products } \\
\text { M. deviance }\end{array}$ \\
\hline Between crosses & 3 & $2201.4^{* * *}$ & $2614.3^{* * *}$ & $167.5^{* * *}$ \\
Between restriction enzymes & 1 & $233.8^{* * *}$ & $326.8^{* * *}$ & $28.2^{* * *}$ \\
Crosses by restriction enzymes & 3 & 237.0 & 42.0 & $6.5^{*}$ \\
Error & 198 & 577.1 & 40.4 & 2.6 \\
\hline
\end{tabular}

*** $P<0.001 ; * * P<0.01 ;{ }^{*} P<0.05$.

236 using EcoRI and 162 using PstI. The Blenheim allele was dominant for 105 of the EcoRI and 82 of the PstI markers and a chi-squared test for the distribution of dominant alleles between the two enzymes showed no significant association $\left(\chi_{1}^{2}=\right.$ $1.45 ; P=0.23)$. Together with the 120 markers previously used for map construction (Thomas et al., 1995b) in this population, 518 markers were now available for mapping. Thirty-eight of the markers were discarded, mainly because they either showed no significant linkage with any other marker at LOD 6.0 or formed a small linkage group of four or fewer markers. Nine of these were putative chromosomespecific RFLPs (PBI30x, PBI30y and PBI30z; PSR100 and PBI24; PSR1077, WG178 and ABG377; and ABG390 on chromosomes 1, 2, 3 and 7, respectively), 21 were AFLPs, six were RAPDs and two were isozyme markers. Fifteen individual linkage groups remained and it was possible to merge some of these by reducing the LOD to 3.0 resulting in 12 groups. These groups were assigned to chromosomes on the basis of chromosome-specific RFLPs. Two groups were ambiguous in that they contained two markers that had been previously assigned to different chromosomes. Thomas et al. (1995b) assigned a small segment consisting of two RAPDs and one RFLP (WG282) to chromosome 6b as WG282 was a chromosome 6 marker (Heun et al., 1991). However, with the additional data, this group was found to contain a microsatellite within the Rubisco activase GenBank sequence HVRCABG which had previously been reported on chromosome 4 (Becker \& Heun, 1995). As several of the AFLP products located in this group were also found to be present on chromosome 4 of the Dicktoo $\times$ Morex linkage map (unpublished data), this group was re-assigned to chromosome segment $4 \mathrm{~b}$. The other ambiguous group contained $\mathrm{CDO} 36$ which had been mapped to barley chromosome 1 (Heun et al., 1991) and MWG546 which had been mapped to chromosome 3 (Graner et al., 1991). Neither of these RFLPs showed any significant linkage with any other chromosome-specific RFLPs and none of the AFLPs in this group was segregating in other mapping populations. However, some of the AFLPs showed significant linkage at LOD 3.0 with markers in the region of PSR687 on chromosome 2, so this group has been tentatively assigned as chromosome segment $2 \mathrm{~b}$. In constructing the maps from these linkage groups, 129 markers were excluded after the second cycle. These comprised 109 AFLPs, 11 RAPDs, five RFLPs and four other markers, resulting in maps constructed from 268 AFLPs, 34 RAPDs, 38 RFLPs and 11 other markers.

Sixty-two markers covered $176.9 \mathrm{cM}$ on chromosome 1 (Fig. 2). This arose from the joining of segments 1a, 1c and 1d of a previous study (Thomas et al., 1995b) through the inclusion of AFLP 


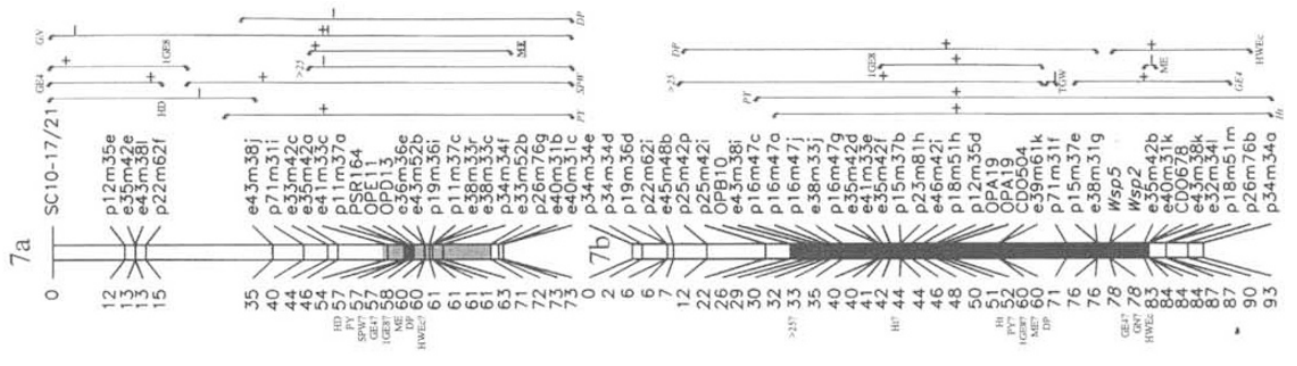

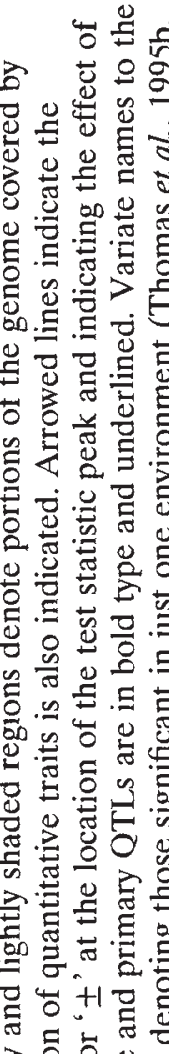
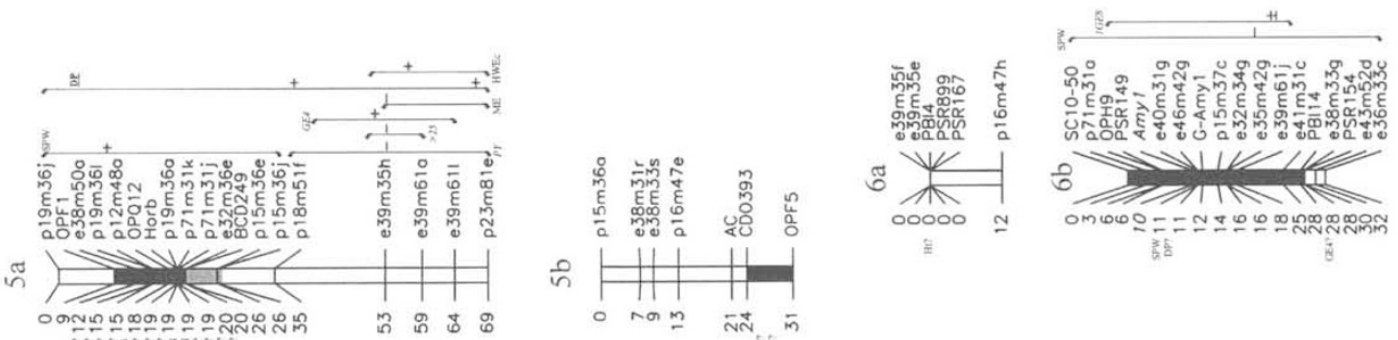

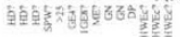
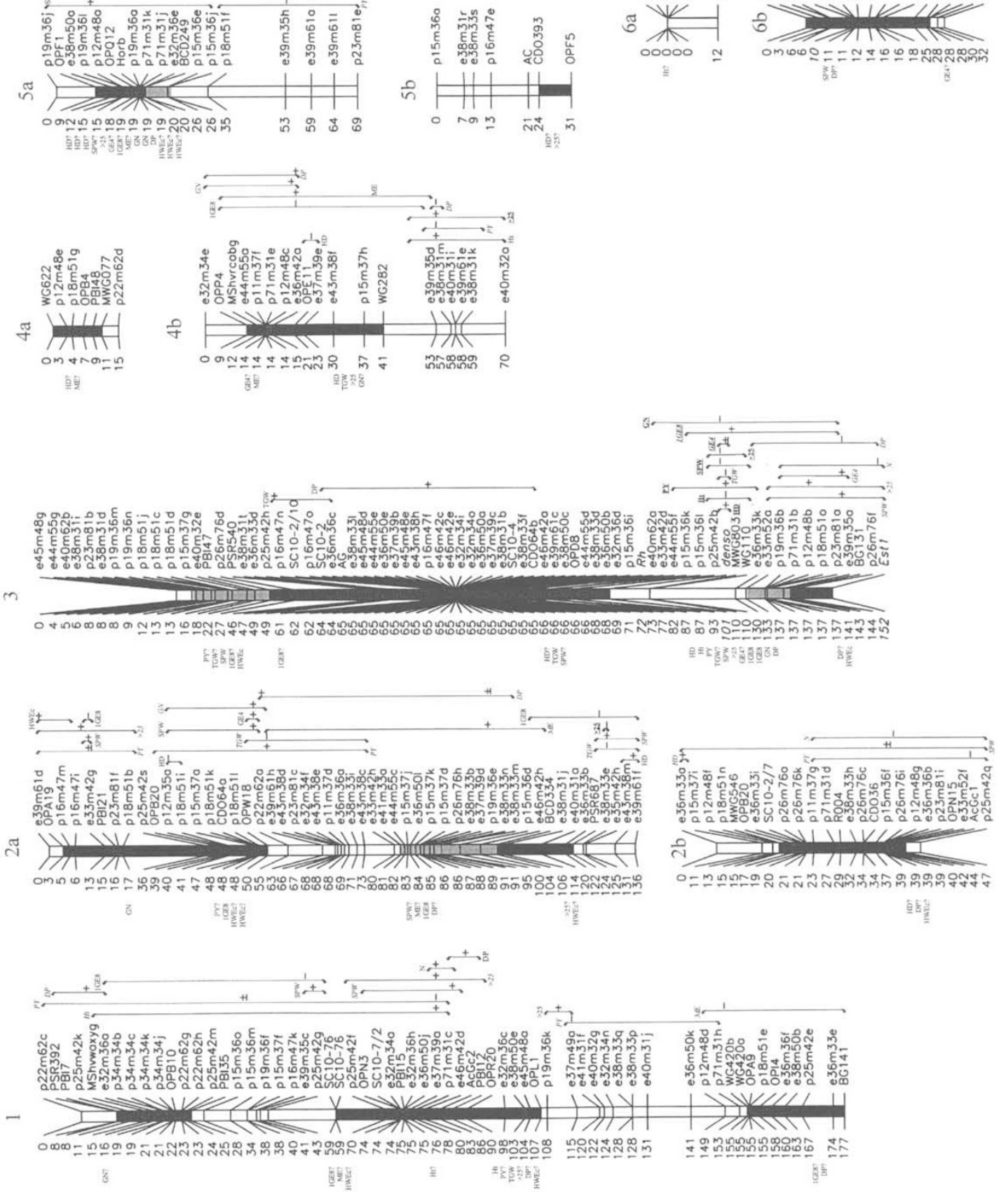

곡용.

王으..

的氙要

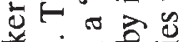

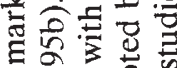

눙긍웡

过范

鞄产

岁造娄

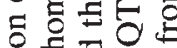

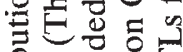

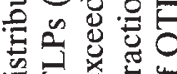

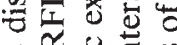

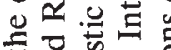

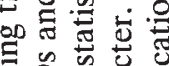

कि कि

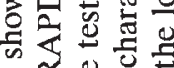

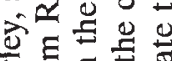

焉

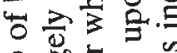

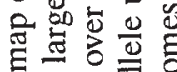

0 造

๘

记吉

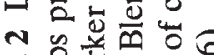

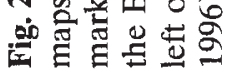


markers. Similarly, chromosome segments $2 \mathrm{a}$ and $2 \mathrm{~b}$ and $3 \mathrm{~b}$ and $3 \mathrm{c}$ of Thomas et al. (1995b) were also joined to form segments 136.1 and $152.3 \mathrm{cM}$ long, respectively, (Table 4; Fig. 2). A marker (SC1017/21) from a previously unassigned segment (Ua) (Thomas et al., 1995b) was linked to chromosome segment 7a with the AFLPs to form a segment 72.7 $\mathrm{cM}$ long (Fig. 2). The other marker in segment $\mathrm{Ua}$ was not linked to any other marker at LOD 6.0 and only linked with SC10-17/21 above LOD 4.0 and so was excluded from the linkage group. At LOD 3.0, there was no other bridging of the other groups previously reported by Thomas et al. (1995b) although some were extended (Table 4; Fig. 2).

Overall, the map covers $906.2 \mathrm{cM}$ compared to under $700 \mathrm{cM}$ constructed mainly with RAPDs and RFLPs (Thomas et al., 1995b). However, the Haldane function was used to produce the latter map and, if the Kosambi function is used, the RAPD and RFLP map covers $502 \mathrm{cM}$ (Table 4). The inclusion of AFLPs in the data set has produced bridges and extensions of $420 \mathrm{cM}$ when compared to the previous map. Some of the markers used to construct the RAPD and RFLP maps were excluded after the second cycle of mapping by JOINMAP but if we include the results from the third cycle of mapping, we can directly compare the lengths spanned by the regions reported by Thomas et al. (1995b) and the present study (Table 4; Fig. 2). The map distances are very similar with or without inclusion of AFLPs (Table 4) so the greater genome coverage is unlikely to be caused by map extension in these regions. Fifty-two EcoRI and 43 PstI AFLP markers were found in the bridges and extensions with 91 EcoRI and 82 Pst I markers in the previously mapped areas. These values are significantly different from those expected from a random distribution $\left(\chi_{1}^{2}=12.79 ; \quad P=0.005\right)$ with fewer markers than expected in the bridges and extensions. However, there was no significant difference between the distributions of EcoRI and PstI markers across the two regions $\left(\chi_{1}^{2}=0.11 ; P=0.74\right)$.

Microsatellites, isozymes, proteins, a Rhynchosporium resistance locus and a morphological marker were amalgamated into one group and compared to AFLP, RFLP and RAPD marker groups. The numbers for linkage groups smaller than $30 \mathrm{cM}$ were summed and a contingency chi-squared calculated which showed no significant interaction between linkage groups and marker classes $\left(\chi_{30}^{2}=38.0\right.$; $P=0.15)$. The distribution of AFLPs is therefore no different from the other markers. We can further classify the AFLPs into those produced with either EcoRI or PstI and into those where the dominant
Table 4 Distances (cM) spanned by markers mapped by Thomas et al. (1995b) ('old') and after addition of AFLPs in these ('previous') and new regions ('bridges and extensions')

\begin{tabular}{|c|c|c|c|c|}
\hline \multirow[b]{2}{*}{ Chr.' } & \multirow[b]{2}{*}{ Old } & \multicolumn{3}{|c|}{ New } \\
\hline & & Previous & $\begin{array}{l}\text { Bridges \& } \\
\text { extensions }\end{array}$ & Total \\
\hline 1 & 80.8 & 87.3 & 89.6 & 176.9 \\
\hline $2 a$ & 84.4 & 87.4 & 48.7 & 136.1 \\
\hline $2 b$ & 26.4 & 25.3 & 21.6 & 46.9 \\
\hline $3 b$ & 117.5 & 116.1 & 36.2 & 152.3 \\
\hline $4 a$ & 14.6 & 11.2 & 3.8 & 15.0 \\
\hline $4 b$ & 34.4 & 31.7 & 37.8 & 69.5 \\
\hline $5 a$ & 22.0 & 16.7 & 52.6 & 69.3 \\
\hline $5 b$ & 12.8 & 7.5 & 23.9 & 31.4 \\
\hline $6 a$ & 0 & 0 & 11.6 & 11.6 \\
\hline $6 b$ & 28.8 & 28.3 & 3.3 & 31.6 \\
\hline $7 \mathrm{a}$ & 23.7 & 16.9 & 55.8 & 72.7 \\
\hline $7 b$ & 56.2 & 58.3 & 34.6 & 92.9 \\
\hline Total & 501.6 & 486.7 & 419.5 & 906.2 \\
\hline
\end{tabular}

Chr., chromosome.

product came from either Blenheim or E224/3. There was a 'borderline' significant contingency chi-squared for the distribution of the AFLPs produced by the two different enzymes across the 11 groups $\left(\chi_{10}^{2}=19.5 ; P=0.04\right)$. This was largely caused by discrepancies in the distribution of products in linkage groups $2 \mathrm{~b}$ and 3 , suggesting that the two enzymes can generate polymorphism in different regions of the genome. However, there was no difference in the origin of the dominant AFLP products over the 11 groups $\left(\chi_{10}^{2}=7.0 ; P=0.73\right)$.

\section{Location of quantitative traits}

Results from the MQTL analyses based on the complete mapping information are summarized in Table 5. Thirteen primary QTL inferences, 12 of which were main effects, and 77 secondary QTL inferences, 29 of which were main effects, were detected for the 12 characters. The main effects accounted for over 30 per cent of the phenotypic variation for nine of the characters. The average phenotypic variation accounted for when interactions were included was 53 per cent and the range was from 87 per cent for $\mathrm{Ht}$ to 22 per cent for HWEc. The percentages of phenotypic variation accounted for by the main effects and interactions were less than those detected in the previous studies for $\mathrm{HD}, \mathrm{Ht}$, TGW, 1GE8, GN and HWEc (Thomas 
Table 5 Numbers of QTLs detected by MOTL using primary and secondary inferences for each character and the percentages of phenotypic variation accounted for by QTL main effects and QTL $\times E$ interactions compared to the average amount detected by single environment regression analysis (Thomas et al., 1995b, 1996)

\begin{tabular}{|c|c|c|c|c|c|c|c|c|c|c|c|c|}
\hline \multirow[b]{3}{*}{ Character } & \multicolumn{4}{|c|}{ Main effect QTLs } & \multicolumn{5}{|c|}{ Interaction QTLs } & \multirow{2}{*}{\multicolumn{3}{|c|}{ Per cent phenotypic variation }} \\
\hline & \multicolumn{2}{|c|}{ Primary } & \multicolumn{2}{|c|}{ Secondary } & \multicolumn{2}{|c|}{ Primary } & \multicolumn{3}{|c|}{ Secondary } & & & \\
\hline & + & - & + & - & + & \pm & + & - & \pm & Main effects & and interactions & Previous analysis \\
\hline $\mathrm{HD}$ & 1 & & 1 & 3 & & & & 1 & & 37 & 53 & 72 \\
\hline $\mathrm{Ht}$ & & 1 & 1 & & & & 2 & & & 83 & 87 & 90 \\
\hline PY & 1 & & & & & & 3 & 5 & 2 & 52 & 66 & 64 \\
\hline TGW & & & 1 & 1 & & & & 3 & & 32 & 36 & 44 \\
\hline SPW & & 1 & 3 & 1 & & & 4 & & 2 & 44 & 57 & 53 \\
\hline$>25$ & 1 & 2 & 1 & & & & 4 & 2 & & 43 & 57 & 57 \\
\hline GE4 & & & 2 & & & 1 & 3 & & & 16 & 42 & 30 \\
\hline 1GE8 & & & 2 & 4 & 1 & & 1 & & & 24 & 45 & 59 \\
\hline $\mathrm{ME}$ & 1 & & 1 & 2 & & & 1 & 1 & & 47 & 50 & 48 \\
\hline GN & & 1 & 1 & & & & 2 & 3 & 1 & 50 & 58 & 69 \\
\hline DP & 2 & & 1 & 1 & & & 4 & 3 & 1 & 35 & 63 & 58 \\
\hline HWEc & & & 3 & & & & & & & 11 & 22 & 58 \\
\hline Total & 6 & 5 & 17 & 12 & 1 & 1 & 24 & 18 & 6 & & & \\
\hline
\end{tabular}

+ and - indicate the effect of alleles from Blenheim upon a trait. \pm indicates a cross-over interaction where significant effects from Blenheim were positive in one environment and negative in another.

et al., 1995b, 1996). For the remainder, the percentages were the same or slightly greater, apart from GE4, where considerably more variation was accounted for by sCIM analysis (Table 5). The average Test Statistic for main effects was permuted to be equivalent to LOD 7.7, ranging from values equivalent to LOD 4.1 for GE4 to LOD 10.9 for $\mathrm{Ht}$. For QTL $\times E$ interactions, the average Test Statistic was lower, equivalent to LOD 2.7 with a range equivalent to 0.7 for $\mathrm{Ht}$ to 5.2 for $\mathrm{HWEc}$.

Positive and negative QTLs were identified in each parent for each character apart from HWEc, where all the positive QTLs were derived from Blenheim and possibly GE4, where the primary QTL was a cross-over interaction and all the other Blenheim alleles gave an increase in the character (Table 5). With these possible exceptions, this confirms the dispersion of QTLs between parents leading to the transgressive segregation reported in previous studies of this cross (Thomas et al., 1995b, 1996). More than 67 per cent of the phenotypic variation accounted for by the SCIM analysis was attributable to main effects for most of the characters, the exceptions being GE4, 1GE8, DP and HWEc (Table 5).

There appear to be a number of QTL 'hot-spots' where the region around a particular marker was found to be involved in the control of a number of characters. This is particularly noticeable on chromosome 2 where three such regions were found, each involved in the control of four or more characters (Fig. 2). The region around denso on chromosome 3 was also important, being involved in the control of all the characters in the current study apart from ME and HWEc. Both arms of chromosome 7 were also important with a 'hot-spot' around $\mathrm{e} 41 \mathrm{~m} 33 \mathrm{c}$ on the short arm being involved in the control of six characters. The long arm of chromosome 7 was also involved in the control of nine characters but, apart from some clustering around p18m51h, these QTLs were spread more evenly over the chromosome. In contrast, chromosome 1 had the longest map length of any segment but, apart from a region around $e 37 \mathrm{~m} 39 \mathrm{a}$, showed no great clustering of QTLs. Eight of the primary QTLs were located in the region around denso, probably reflecting the action of a major developmental gene (Fig. 2).

\section{Discussion}

Several reports have now demonstrated that AFLPs are a reliable and reproducible molecular marker assay. Furthermore, large numbers of AFLP loci can be detected in a single experiment providing an experimental system capable of generating vast numbers of informative markers. Most experiments reported to date have focused on EcoRI/MseI 
digested DNA and associated adaptors but HindIII/ MseI and PstI/MseI have also been used in potato (Meksem et al., 1995) and tomato (Thomas et al., 1995a). Our results indicate that $P_{s t} \mathrm{I} / \mathrm{MseI}$ primers are more efficient in detecting polymorphism than EcoRI/MseI primers in barley. This is an important observation because it will improve the cost-effectiveness of deploying AFLP technology in barley genetics. The Blenheim $\times$ E224/3 population is the least polymorphic intraspecific cross examined but nearly 400 AFLP markers were added to the data set used to produce the linkage map based on RFLP and RAPD markers (Thomas et al., 1995b).

Contingency chi-squared tests revealed that the distributions of EcoRI/MseI- and Pst I/MseI-generated polymorphic products between linkage groups were different. An examination of the distribution of the AFLPs detected by the different enzyme combinations within the genome also revealed a nonrandom distribution of data points.

Pst $\mathrm{I}$ is a methylation-sensitive enzyme and there is a possibility that some of the observed polymorphisms were influenced by methylation changes. In plants, 5-methyl cytosine is the most common methylated base occurring in up to 30 per cent of all C (Gruenbaum et al., 1981) in plants and an estimated 25.7 per cent in barley (Amasino et al., 1990b). Changes in methylation status have been reported previously in barley when $\mathrm{HpaII}$ - and MspIdigested DNA from anther-culture derived doubled haploids of cv. Igri was screened with seven RFLP probes (Devaux et al., 1993). In that case 11.7 per cent of the assays performed (49 out of 420) revealed polymorphism based on a methylation change. These polymorphisms appeared to be distributed randomly amongst the DHs examined but not amongst the probes.

Overall, the AFLP markers filled gaps in the previously constructed map (Thomas et al., 1995b), providing good genome coverage. A previous study (Becker et al., 1995) with barley AFLPs reported evidence of map extension. In our study increase in map length by the inclusion of AFLP markers was caused by map extension in specific regions of the genome that were poorly represented by RFLP and RAPD markers.

A major consideration is the usefulness of the AFLP data generated in localizing quantitative traits. Good overall agreement in the location of QTL to chromosomal segments is observed between previous (Thomas et al., 1995b, 1996) studies based on RAPD and RFLP maps, and the present study which included AFLPs (Fig. 2). With some exceptions, the QTL in the current study are either in the same segment or in an adjacent segment which has been newly mapped. Thirty-three QTL peaks are located outside regions covered by the RAPD and RFLP map which demonstrated that these regions were also important in the control of traits.

In conclusion, AFLPs provide a fast and reproducible method for producing linkage maps in breeding populations which have a relatively narrow genetic base. The technology will allow more effort to be devoted to examining larger segregating populations which are chosen for their biological or breeding relevance rather than the ease with which polymorphism can be detected. Finally, because the polymorphism detected with AFLPs is analogous to that revealed by RFLPs (restriction site variation) greater emphasis can be placed on comparative mapping between different barley populations.

\section{Acknowledgements}

The authors gratefully thank the Scottish Office Agriculture, Environment and Fisheries Department for funding this work.

\section{References}

AMASINO, R. M., JOHN, M. C., KLAAS, M. AND CROWELL, D. M. 1990. Role of DNA methylation in the regulation of gene expression in plants. In: Clawson G. A., Willis, D. B., Weisbach, A. and Jones, P. (eds) Nucleic Acid Methylation, pp. 187-198. Wiley-Liss, New York.

BECKER, J. AND HEUN, M. 1995. Barley microsatellites: allele variation and mapping. Plant Mol. Biol., 27, $835-845$.

BECKER, J., VOS, P., KUIPER, M., SALAMINI, F. AND HEUN, M. 1995. Combined mapping of AFLP and RFLP markers in barley. Mol. Gen. Genet., 249, 65-73.

BOTSTEIN, D., WHITE, R. L., SKOLNICK, M. H. AND DAVIS, R. w. 1980. Construction of a genetic map in man using restriction fragment length polymorphisms. Am. J. Hum. Genet., 32, 314-331.

Devaux, P., KILIAN, A. AND KLEINHOFs, A. 1993. Anther culture and Hordeum bulbosum derived barley doubled haploids: mutations and methylation. Mol. Gen. Genet., 241, 674-679.

FOLKERTSMA, R. T., ROUPPE VAN DER VOORT, J. N. A. M., DE GROOT, K. E., VAN ZANDVOORT, P. M., SCHOTS, A., GOMMERS, F. J. ET AL. 1996. Gene pool similarities of potato cyst nematode populations assessed by AFLP analysis. Mol. Pl-Micr. Interact, 9, 47-54.

GRANER, A., JAHOOR, A., SCHONDELMAIER, J., SIEDLER, H., PILLEN, K., FISCHBECK, G. ET AL. 1991. Construction of an RFLP map in barley. Theor. Appl. Genet., 83, 250-256.

GRUENBAUM, Y., NAVEH-MANY, T., CEDAR, H. AND RAZIN, A. 1981. Sequence specificity of methylation in higher plant DNA. Nature, 292, 860-862.

(c) The Genetical Society of Great Britain, Heredity, 79, 48-59. 
HElentJaris, T. AND BURR, B. 1989. Development and Application of Molecular Markers to Problems in Plant Genetics. Current Communications in Molecular Biology. Cold Spring Harbor, Laboratory Press, Cold Spring Harbor, NY.

HEUN, M., KENNEDY, A. E., ANDERSON, J. A., LAPITAN, N. L. V., SORElls, M. E. AND TANKSLEY, S. D. 1991. Construction of a restriction fragment length polymorphism map for barley (Hordeum vulgare). Genome, 34, 437-447.

LIN, J. J. AND kUO, J. 1995. AFLP ${ }^{\mathrm{TM}}$ : A novel PCR-based assay for plant and bacterial DNA fingerprinting. Focus, 17, 51-56.

MEKSEM, K., LEISTER, D., PEPEMAN, J., ZABEAU, M., SALAMINI, F. AND GEBHARDT, C. 1995. A high resolution map on potato chromosome $\mathrm{V}$ based on RFLP and AFLP markers. Mol. Gen. Genet., 249, 74-81.

MULLIS, K., FALOONA, S., SCHRF, S., SAIKI, R., HORN, G. AND ERLICH, H. 1986. Specific enzymatic amplification of DNA in vitro: the polymerase chain reaction. Cold Spring Harb. Symp. Quant. Biol., 51, 263-273.

POWELl, W., MORGANTE, M., VOGEL, J., TINGEY, S. AND RAFALSKI, J. A. 1994. Technology for plant genome analysis and breeding. In: Javornik, B., Bohanec, B. and Kreft, I. (eds) Proc. Int. Colloq. Impact of Plant Biotechnology on Agriculture, pp. 177-180. Planprint, Ljubljana.

POWELL, W., BONAR, N., BAIRD, E., RUSSELL, J. AND WAUGH, R. 1995. Molecular marker techniques for barley genome analysis and breeding. Ann. Rep. Scot. Crop Res. Inst. 1994, 57-58.

POWELl, W. MORGANTE, M., ANDRE, C., HANAFEY, M., VOGEL, J., TINGEY, S. AND RAFALSK1, A. 1996. The utility of RFLP, RAPD, AFLP and SSR (microsatellite) markers for germplasm analysis. Mol. Breed., 2, $225-238$.

RAFALSK1, A. J., MORGANTE, M., VOGEL, J., POWELL, W. AND TINGEY, S. V. 1996. Generating new DNA markers in plants. In: Birren, B. and Lai, E. (eds) Analysis of Non-mammalian Genomes, pp. 75-129, Academic Press, London.

SAGHAI-MAROOF, M. A., SOliman, K. M., JORGENSEN, R. A. AND ALlARD, R. w. 1984. Ribosomal DNA spacer length polymorphism in barley: Mendelian inheritance, chromosomal location and population dynamics. Proc. Natl. Acad. Sci. U.S.A., 81, 8014-8018.

STAM, P. AND VAN OOIJEN, J. W. 1995. Joinmap (tm) version 2.0: Software for the calculation of genetic linkage maps. CPRO-DLO, Wageningen.

TAUTZ, D. 1989. Hypervariability of simple sequences as a general source for polymorphic DNA markers. $\mathrm{Nucl}$. Acids Res., 17, 6463-6471.

THOMAS, w. T. B., POWELl, W. AND SWANSTON, J. S. 1991. The effects of major genes on quantitatively varying characters in barley. 4. The GPert and denso loci and quality characters. Heredity, 66, 381-389.

THOMAS, C. M., VOS, P., ZABEAU, M., JONES, D. A., NORCOTT, K. A., CHADWICK, B. P. AND JONES, J. D. G. 1995a. Identification of amplified restriction fragment polymorphism (AFLP) markers tightly linked to the tomato $C f-9$ gene for resistance to Cladosporium fulvum. Plant J., 8, 785-794.

THOMAS, W. T. B., POWEll, W., WAUGH, R., CHALMERS, K. J., BARUA, U. M., JACK, P. ET AL. 1995b. Detection of quantitative trait loci for agronomic, yield, grain and disease characters in spring barley (H. vulgare L.). Theor. Appl. Genet., 91, 1037-1047.

THOMAS, W. T. B., POWELl, W., SWANSTON, J. S., Ellis, R. P., CHALMERS, K. J., BARUA, U. M. ET AL. 1996. Quantitative trait loci for germination and malting quality characters in a spring barley cross. Crop Sci., 36, 265-273.

TINKER, N. A. AND MATHER, D. E. 1995. Methods for QTL analysis in progeny replicated in multiple environments. J. Quant. Trait Loci, http: //probenalusda.gov: 8000/otherdocs/jqtl/jqtl1995-01/jqtl15.html

TINKER, N. A., MATHER, D. E., ROSSNAGEL, B. G., KASHA, K. J., KLEINHOFS, A., HAYES, P. ET AL. 1996. Regions of the genome than affect agronomic performance in two row barley. Crop Sci., 36, 1053-1062.

vos, P., HOGERS, R., BLEEKER, M., REIJANS, M., VAN DER LEE, T., HORNES, M. ET AL. 1995. AFLP: a new concept for DNA fingerprinting. Nucl. Acids Res., 23, 4407-4414.

WEBER, J. AND MAY, P. E. 1989. Abundant class of human DNA polymorphisms which can be typed using the polymerase chain reaction. Am. J. Hum. Genet., 44, 388-396.

WELSH, J. AND McClELland, J. 1990. Fingerprinting genomes using PCR with arbitrary primers. Nucl. Acid. Res., 18, 6531-6535.

WILLIAMS, J. G. K., KUBELIK, A. R., LIVAK, K. J., RAFALSK1, A. J. AND TINGEY, s. V. 1990. DNA polymorphisms amplified by arbitrary primers are useful as genetic markers. Nucl. Acids Res., 18, 6531-6535.

ZABEAU, M. AND VOS, P. 1993. Selective restriction fragment amplification: a general method for DNA fingerprinting. European Patent Application 92402629.7. Publication Number EP 0534858 A1. 


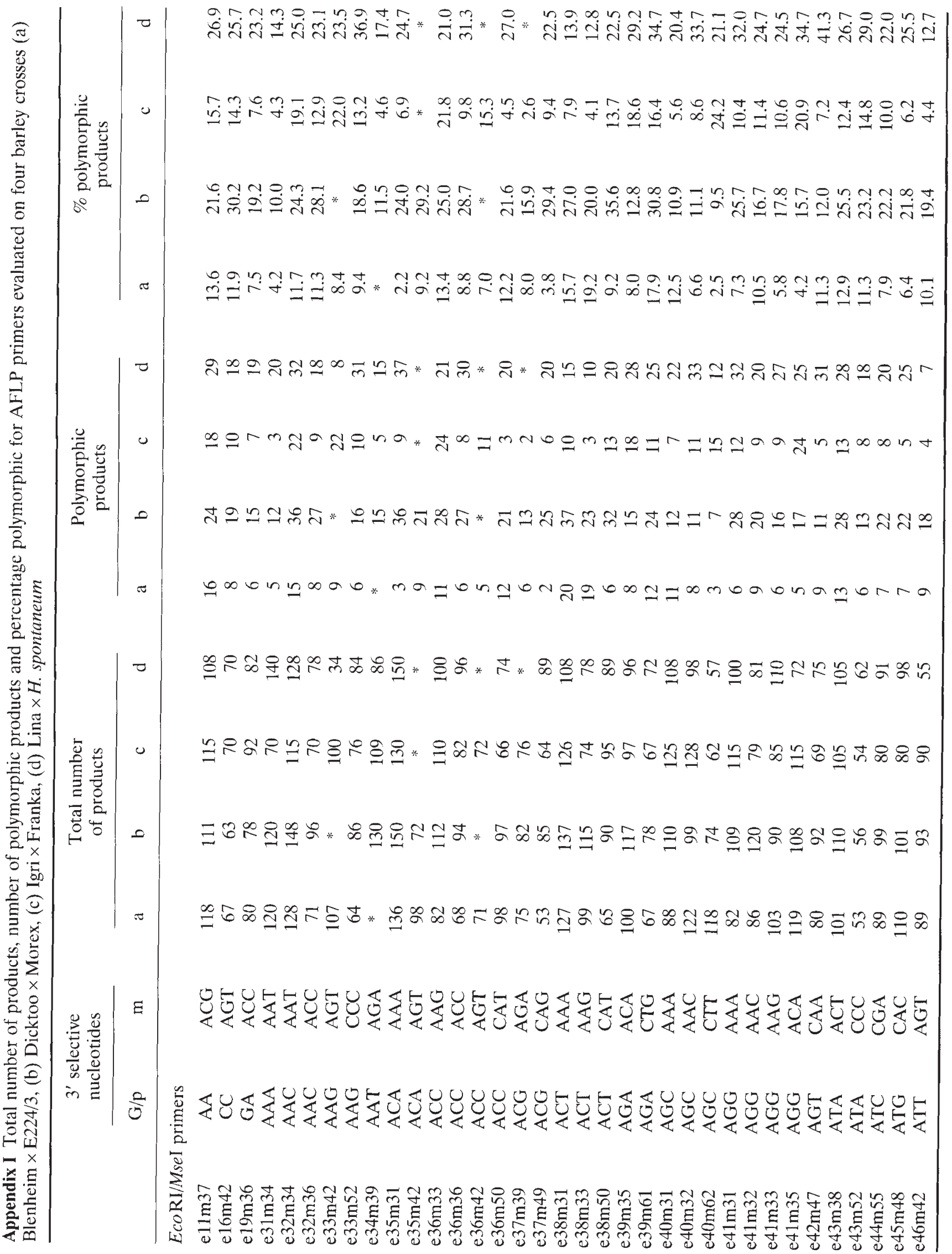

(c) The Genetical Society of Great Britain, Heredity, 79, 48-59. 


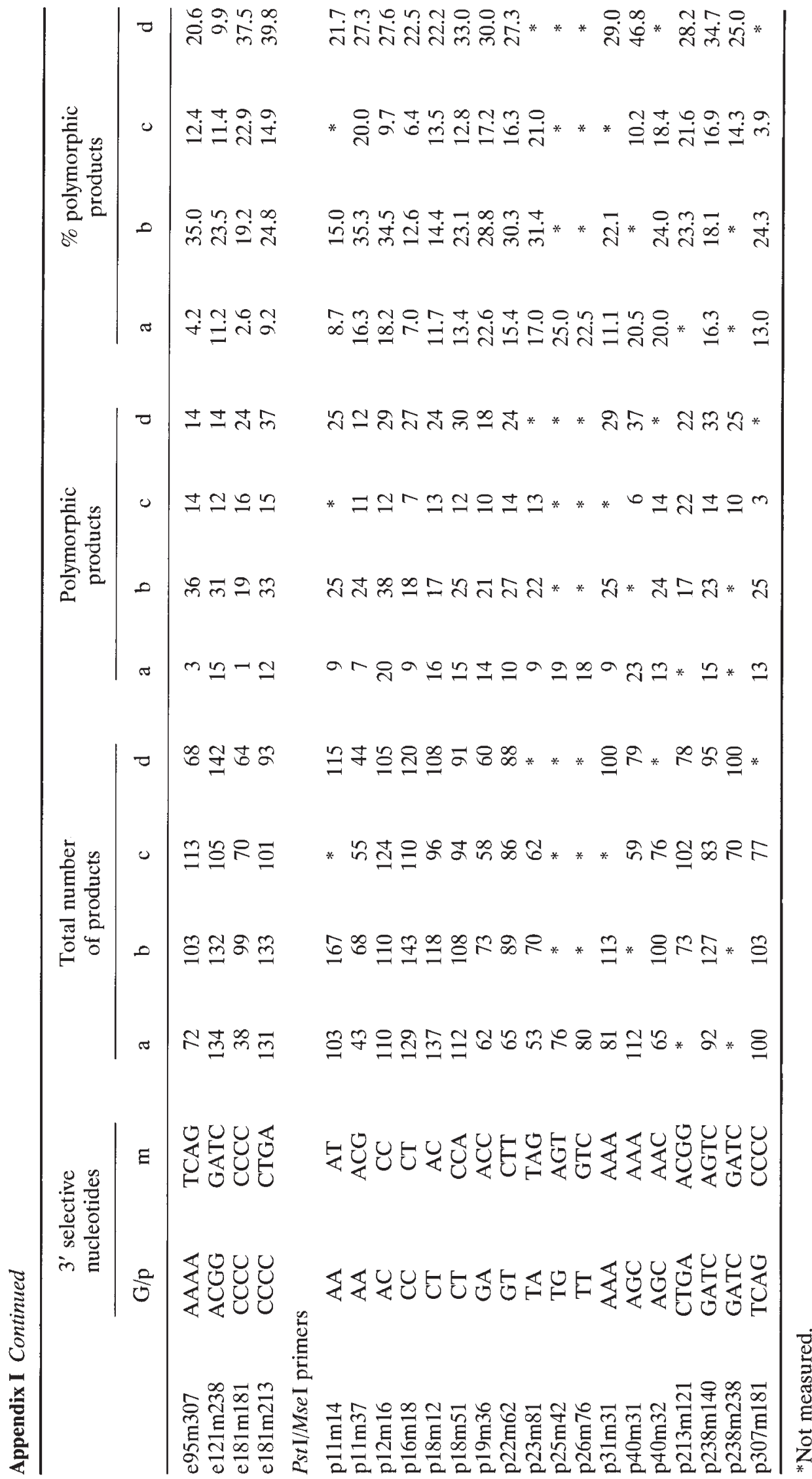

(C) The Genetical Society of Great Britain, Heredity, 79, 48-59. 